\title{
Effect of Filament Winding Methods on Surface Roughness and Fiber Volume Fraction of $\mathrm{SiC}_{\mathrm{f}} / \mathrm{SiC}$ Composite Tubes
}

\author{
Daejong Kim*^, Jongmin Lee ${ }^{* * *}$, Ji Yeon Park*, and Weon-Ju Kim* \\ *Nuclear Materials Division, Korea Atomic Energy Research Institute, Daejeon 305-353, Korea \\ **Department of Materials Engineering, College of Engineering, Chungnam National University, Daejeon 305-764, Korea \\ (Received Septembe 13, 2013; Revised November 12, 2013; Accepted November 15, 2013)
}

\section{$\mathrm{SiC}_{\mathrm{f}} / \mathrm{SiC}$ 복합체 튜브의 표면조도 및 섬유 부피 분율에 미치는 필라멘트 와인딩 방법의 영향}

\author{
김대종*, · 이종민**** 박지연* · 김원주* \\ *한국원자력연구원 원자력재료개발부 \\ **충남대학교 재료공학과 \\ (2013년 9월 13일 접수 ; 2013년 11월 12일 수정 ; 2013년 11월 15일 채택)
}

\begin{abstract}
Silicon carbide and its composites are being considered as a nuclear fuel cladding material for LWR nuclear reactors because they have a low neutron absorption cross section, low hydrogen production under accident conditions, and high strength at high temperatures. The $\mathrm{SiC}$ composite cladding tube considered in this study consists of three layers, monolith $\mathrm{CVD} \mathrm{SiC}-\mathrm{SiC} / \mathrm{SiC}$ composite -monolith CVD SiC. The volume fraction of SiC fiber and surface roughness of the composite layer affect mechanical and corrosion properties of the cladding tube. In this study, various types of $\mathrm{SiC}$ fiber preforms with tubular shapes were fabricated by a filament winding method using two types of Tyranno SA3 grade SiC fibers with 800 filaments/yarn and 1600 filaments/yarn. After chemical vapor infiltration of the $\mathrm{SiC}$ matrix, the surface roughness and fiber volume fraction were measured. As filament counts were changed from 800 to 1600 , the surface roughness increased but the fiber volume fraction decreased. The $\mathrm{SiC}_{\mathrm{f}} / \mathrm{SiC}$ composite with a bamboo-like winding pattern has a smaller surface roughness and a higher fiber volume fraction than that with a zigzag winding pattern.
\end{abstract}

Key words: Silicon carbide, Filament winding, Surface roughness, Fiber volume fraction

\section{1. 서 론}

탄화규소 $(\mathrm{SiC})$ 는 우수한 고온 기계적 특성, 낮은 중성 자 흡수 단면적, 높은 중성자 조사특성 및 고온 수화학 환경에서의 내부식성 등으로 인하여 가압형 경수로 (pressurized light water reactor, LWR)의 핵연료 피복관 (nuclear fuel cladding) 재료로 사용되기 위한 연구가 진행 되고 있다. ${ }^{1-5)} \mathrm{SiC}$ 및 $\mathrm{SiC}$ 복합체를 기본으로 하는 $\mathrm{LWR}$ 피복관은 핵분열 생성물을 담지하는 기능의 단미 $\mathrm{SiC}$ 내 층, 인성 및 기계적 강도를 높여주기 위한 $\mathrm{SiC}_{\mathrm{f}} / \mathrm{SiC}$ 복합 체 중간층, 원자로 수화학(water chemistry) 환경으로부터 복합체층을 보호하기 위한 단미 $\mathrm{SiC}$ 외층으로 구성된다 (Fig. 1), 이들 중에서 중간층인 $\mathrm{SiC}_{\mathrm{f}} / \mathrm{SiC}$ 복합체층은 화학

${ }^{\dagger}$ Corresponding author : Daejong Kim

E-mail : dkim@kaeri.re.kr

Tel : +82-42-868-4559 Fax : +82-42-862-8549 기상침착법(chemical vapor infiltration, $\mathrm{CVI}$ )에 의해 제조 된 $\mathrm{SiC}_{\mathrm{f}} / \mathrm{SiC}$ 복합체가 가장 우수한 내조사(neutron irradiation resistance) 특성을 보이고 있으며, ${ }^{6,7)}$ 강화 섬유는 불 순물의 함량이 낮아 중성자 흡수 단면적이 낮고, 기계적 특성이 우수한 Hi-Nicalon Type S와 Tyranno SA3가 유력 하게 거론되고 있다.

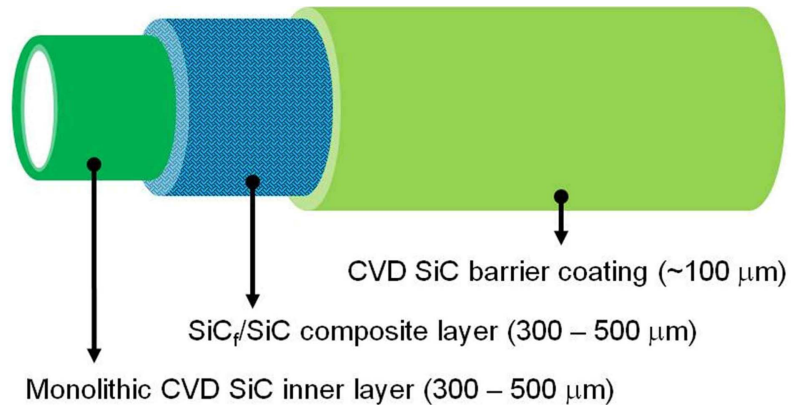

Fig. 1. Design concept of a multi-layered $\mathrm{SiC}$ composite for the LWR fuel cladding. ${ }^{2)}$ 
복합체 중간층을 제조하기 위해서는 $\mathrm{CVD} \mathrm{SiC}$ 내층 위 에 $\mathrm{SiC}$ 섬유 프리폼(preform)을 제조해야 한다. 얇은 관 형태로 장섬유강화 복합체를 제조하기 위해서는 브레이 딩(braiding) 또는 필라멘트 와인딩(filament winding) 방법 이 적합하며, ${ }^{8,9)}$ 약 $400 \mu \mathrm{m}$ 두께 이하로 복합체층을 제조 할 경우 섬유의 종류 및 권선 방법에 따라 1 2층 정도만 적층될 수 있다.

따라서, 복합체 권선 방법의 선택 및 패턴의 균일성은 핵연료 피복관용 복합체 특성에 매우 중요한 특성 중에 하나이며, 기공의 분포 및 기지상 채움에 큰 영향을 미칠 수 있다. 특히 CVD SiC 외층의 경우 $100 \mu \mathrm{m}$ 미만의 두 께를 가지게 되는데, 표면조도(surface roughness)가 클 경 우, 복합체 최종 가공 시 복합체 중간층이 노출되는 문제 점을 야기할 수 있기 때문에 표면조도를 최소화 할 필요 가 있다. 또한, 복합체층 제조시 $\mathrm{SiC}$ 섬유의 권선 패턴에 따라 $\mathrm{SiC}$ 섬유의 부피 분율이 변화할 수 있고, 기지상 침 착 거동에도 영향을 미치기 때문에 결과적으로 기계적 특 성이 변할 수 있다. ${ }^{10,11)}$

따라서, 본 연구에서는 다양한 필라멘트 와인딩법으로 제조된 $\mathrm{SiC}_{\mathrm{f}} / \mathrm{SiC}$ 복합체의 섬유 부피 분율과 표면조도를 분석하고 최적의 튜브형 프리폼 제조방법을 도출하고자 하였다.

\section{2. 실험방법}

고순화 처리된 흑연봉에 $\mathrm{SiC}$ 가 약 $300 \sim 330 \mu \mathrm{m}$ 의 두께 로 코팅된 $9.1 \mathrm{~mm}$ 직경의 맨드릴(mandrel)에 $\mathrm{SiC}$ 섬유를 필라멘트 와인딩법으로 $\mathrm{SiC}$ 섬유 프리폼을 제조하였다. 강화 $\mathrm{SiC}$ 섬유는 Tyranno $\mathrm{SA} 3$ (Ube Industries, Japan)가 사 용되었으며, 섬유의 한 가닥(yarn)에 800 필라멘트를 포함 하고 있는 SA3-S1108PX와 1600 필라멘트를 포함하고 있 는 $\mathrm{SA} 3-\mathrm{S} 1116 \mathrm{PX}$ 섬유를 이용하였다. 두 $\mathrm{SiC}$ 섬유 모두 밀도는 $3.10 \mathrm{~g} / \mathrm{cm}^{3}$ 이며, $7.5 \mu \mathrm{m}$ 의 필라멘트 직경을 가진다 . 섬유의 권선을 위해 4축 장비(PICO Co., Korea)를 이용 하였으며, $+55 /-55^{\circ}$ 권선 각도를 가지도록 나사선 형태 (helical)로 제작 되었다. Tyranno $\mathrm{SA} 3 \mathrm{SiC}$ 섬유는 결정질 의 구조를 가지기 때문에 일반적인 $\mathrm{SiC}$ 섬유에 비해 큰 취성을 가진다. 따라서, 권선시 필라멘트의 끊김(peeling) 이 쉽게 발생하며, 섬유에 큰 장력이 부과될 경우 섬유 다발이 완전히 단절되기도 한다. 따라서, 결정질의 $\mathrm{SiC}$ 섬 유를 권선할 때 의도적인 응력은 부과되지 않았으며, $\mathrm{SiC}$ 섬유의 보빈(bobbin)이 회전할 때의 스풀 핀(spool pin)과 의 마찰력에 의해서만 장력이 유지되도록 하였다. 또한, 섬유의 끊김을 줄이기 위해 보빈에서 맨드릴까지 접촉 부 분을 최소화 하였다.

복합체의 부피밀도(bulk density, $\mathrm{D}_{\mathrm{b}}$ )는 섬유 권선 전후 의 질량 변화 $(\Delta \mathrm{m})$ 와 $\mathrm{SiC}$ 기지상을 채운 후 주사전자현미
경(SEM)을 통해 복합체 두께를 측정하여 아래 식 (1)과 같이 부피분율 $(\mathrm{V})$ 로부터 계산되었다.

$$
\mathrm{D}_{\mathrm{b}}\left(\mathrm{g} / \mathrm{cm}^{3}\right)=\Delta \mathrm{m}(\mathrm{g}) / \mathrm{V}\left(\mathrm{cm}^{3}\right)
$$

섬유가 권선된 $\mathrm{SiC}$ 섬유 프리폼의 표면조도 측정을 위 해 접촉식 표면조도기(SV-624, Mitotoyo Co., Japan)를 사 용하였으며, 1 개의 샘플에 대해 4 번 측정하여 평균값을 취했다. 접촉에 의한 섬유의 끊김을 방지하기 위하여, $\mathrm{CH}_{3} \mathrm{SiCl}_{3}$ (methyltrichlorosilane, MTS)를 원료가스로 사용한 $\mathrm{H}_{2}$ 분위기에서 화학기상침착(chemical vapor infiltration, $\mathrm{CVI})$ 법으로 $\mathrm{SiC}$ 기지상을 채운 후 표면조도를 측정하였 다. 수직형 반응로를 이용하여 $\mathrm{CVI}$ 를 수행하였으며, $1000^{\circ} \mathrm{C}$ 의 증착온도에서 $800 \mathrm{sccm}$ 의 총유량, $2.67 \mathrm{kPa}$ 의 증착압력 에서 15 시간 동안 증착이 이루어졌다. 침착 후 복합체층 외부에 코팅된 $\mathrm{SiC}$ 두께는 $20-50 \mu \mathrm{m}$ 가 되도록 시편을 준 비 하였다.

\section{3. 결과 및 고찰}

\subsection{SiC 섬유의 권선 형태}

맨드릴의 직경과 $\mathrm{SiC}$ 섬유 다발의 폭(band width)이 일 정할 경우, 권선 구간의 길이가 변함에 따라 최적 섬유 패턴이 결정이 된다. Fig. 2는 나사선 형태로 권선된 SA3$\mathrm{S} 1108 \mathrm{PX} \mathrm{SiC}$ 섬유의 패턴을 보여 주고 있다. SA3-S1I08PX $\mathrm{SiC}$ 섬유 다발 폭은 $0.965 \mathrm{~mm}$ 로 설정되었으며, 2층(layer)이 권선되었다. 권선 길이를 각각 $95 \mathrm{~mm}, 100 \mathrm{~mm}, 97 \mathrm{~mm}$,
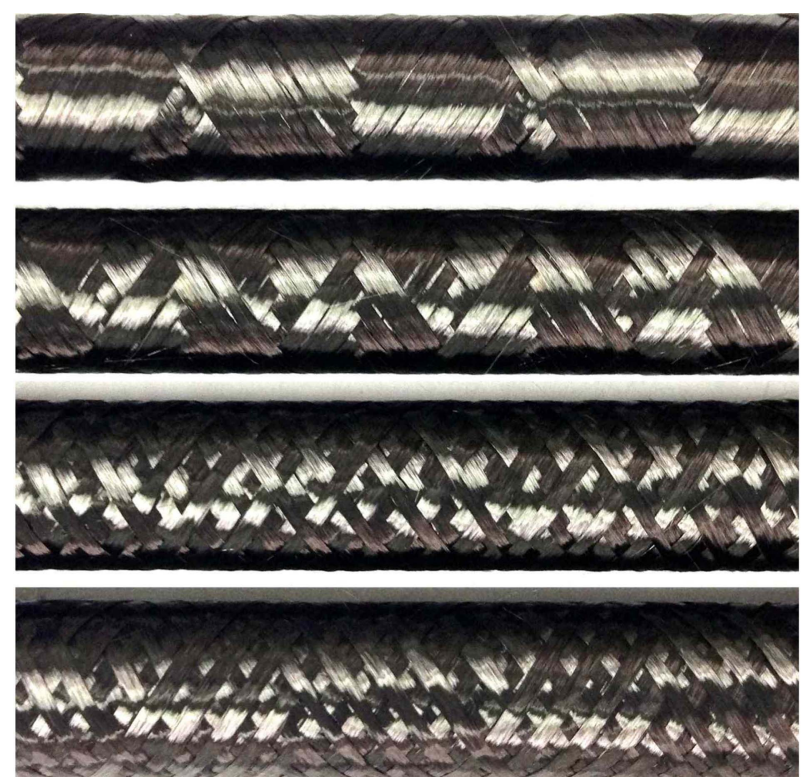

Fig. 2. SiC fiber preforms of SA3-S1I08PX helically wound with winding angle of $+55 /-55^{\circ}$ on the mandrel with $9.1 \mathrm{~mm}$ in diameter. 


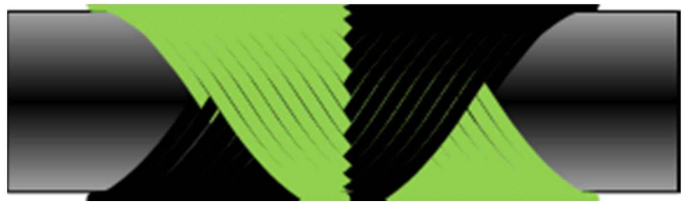

(a)

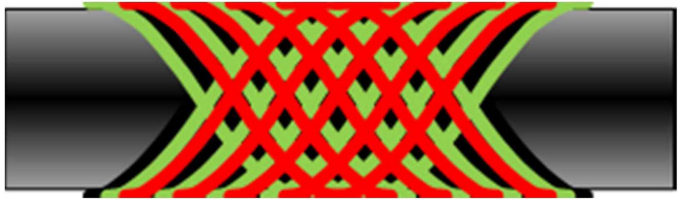

(c)

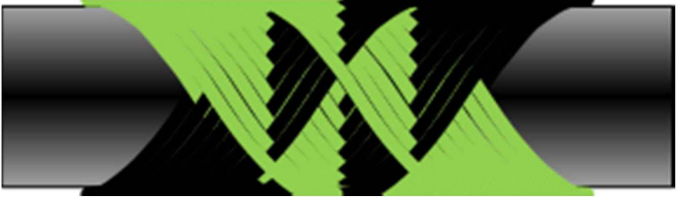

(b)

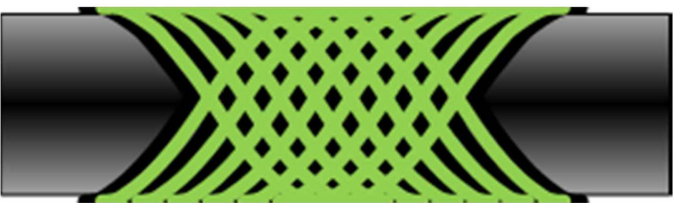

(d)

Fig. 3. Schematics of SiC fiber preforms; (a) 1-return, (b) 2-return, (c) 6-return, and (d) 9-return.

$103 \mathrm{~mm}$ 로 조절함에 따라, 섬유의 패턴은 네 가지 형태로 나타난 것을 볼 수 있다.

Fig. 3은 $\mathrm{SiC}$ 섬유의 권선 패턴의 모식도를 보여 주고 있다. SA3-S1I08PX 섬유를 17회 왕복을 할 때 1층이 완 전히 채워지게 되며, 패턴에 따라 대나무 형상(bamboolike)을 가지거나(Fig. 3(a), (b)), 지그재그(zigzag) 형상을 가지는 것을 볼 수 있다(Fig. 3(c), (d)). 대나무 형상을 가 질 경우 겹치는 부분은 같은 선상의 원주방향으로 일렬 로 정렬되며 총 17 회의 겹침이 발생한다. 1-return 샘플의 경우 첫 번째 왕복 후 두 번째 궤적(fiber trajectory)은 첫 번째 궤적을 바로 인접해서 이루어지며, 순차적으로 빈 곳을 채우게 된다(winding sequence: $1,2,3,4,5 \ldots$ 17). 2-return 샘플은 첫 번째 왕복 후 두 번째 궤적은 첫 번째 궤적 간격(winding pitch)의 $1 / 2$ 지점에서 위치하며, 세 번째 권선 궤적은 첫 번째 섬유 궤적을 인접해서, 네 번째는 두 번째 궤적과 인접해서 권선 된다(winding sequence: $1,3,5,7,9, \ldots 17)$. 두 가지 패턴 모두 1 층은 $+55^{\circ}$ 와 $-55^{\circ}$ 방향을 가지는 1 개의 조밀한 단위 층(sublayer)으로 구성이 된다. 반면 6-return과 9-return 시편의 경우 지그재그 형태를 띄게 되며, 6-return 샘플의 경우 첫 번째 섬유의 권선 후 두 번째는 $1 / 6$ 지점, 7 번째는 첫 번 째 궤적의 인접한 부분으로 오게 된다. 또한, 13 번째 궤 적은 7번째 권선된 섬유의 인접 지점으로 오게 된다. 이 러한 경우 1 층은 전체 면적의 $1 / 3$ 이 권선된 3 개의 단위 층으로 구성된다(winding sequence: $1,7,13,2,8,14 \ldots$ 17). 9-return 샘플의 경우 두 번째 권선 궤적은 첫 번째 궤적의 $1 / 9$ 에 위치하며, 10 번째 궤적은 첫 번째와 9 번째 궤적 사이에 위치하고, 전체 면적의 $1 / 2$ 이 권선된 2 개의 단위 층으로 구성된다 (winding sequence: 1, 10, 2, 11, $3,12 \ldots 17)$.

\section{2. 섬유 권선 방법에 따른 섬유 부피 분율 변화}

Fig. 4는 권선 패턴 및 섬유의 종류에 따른 섬유의 부 피 분율 변화를 보여 주고 있다. SA3-S1I08PX 섬유의 1-

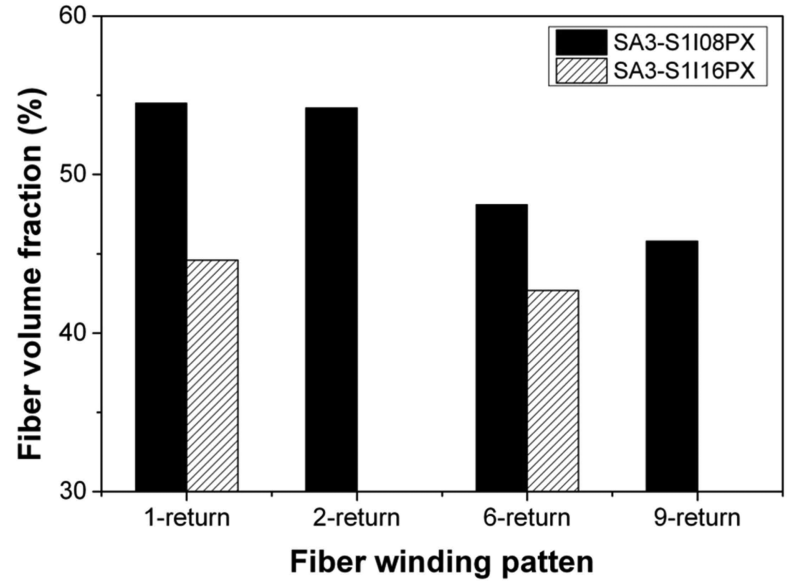

Fig. 4. Volume fraction of $\mathrm{SiC}$ fibers in $\mathrm{SiC}_{\mathrm{f}} / \mathrm{SiC}$ composite tubes.

return과 2-return 샘플의 경우 섬유 부피 분율은 약 $54.4 \%$ 와 $54.2 \%$ 로 거의 동일한 것으로 나타났다. $+55^{\circ}$ 와 $-55^{\circ}$ 권선 각도를 가지는 섬유가 겹치는 부분에서 불규칙적인 공극 이 발생하며, 겹치는 부분은 2-return이 1-return 샘플에 비 해 두 배가 된다. 그러나, 두 샘플의 winding sequence가 거의 동일하고, 겹치는 부분에서의 공극 역시 전체 부피 에 비해 크지 않기 때문에 섬유 부피 분율의 변화는 거 의 없는 것으로 판단된다. 그러나, 6-return과 9-return 샘 플의 경우 섬유의 분율은 각각 $48.1 \%$ 와 $45.8 \%$ 로 크게 감 소하게 된다. 6-return 샘플의 경우 두 번째 단위 층을 $+55^{\circ}$ 방향으로 권선 시, 첫 번째 단위 층은 전체 면적의 $1 / 3$ 만큼 (winding pitch $=2 \times$ fiber band width) $-55^{\circ}$ 방 향으로 섬유가 권선된 상태이며 (Fig. 3(c)), 세 번째 단위 층을 권선 할때 $-55^{\circ}$ 방향으로 $2 / 3$ 면적만큼 섬유가 덮여 있기 때문에 큰 장력으로 두 번째와 세 번째 단위 층을 압착시켜야 한다. 그러나 압착이 완전히 이루어지지 않았 기 때문에 $\mathrm{SiC}$ 섬유 프리폼의 두께는 증가하였으며, 충분 한 장력이 부과되지 않기 때문으로 판단된다. 9-return 샘 


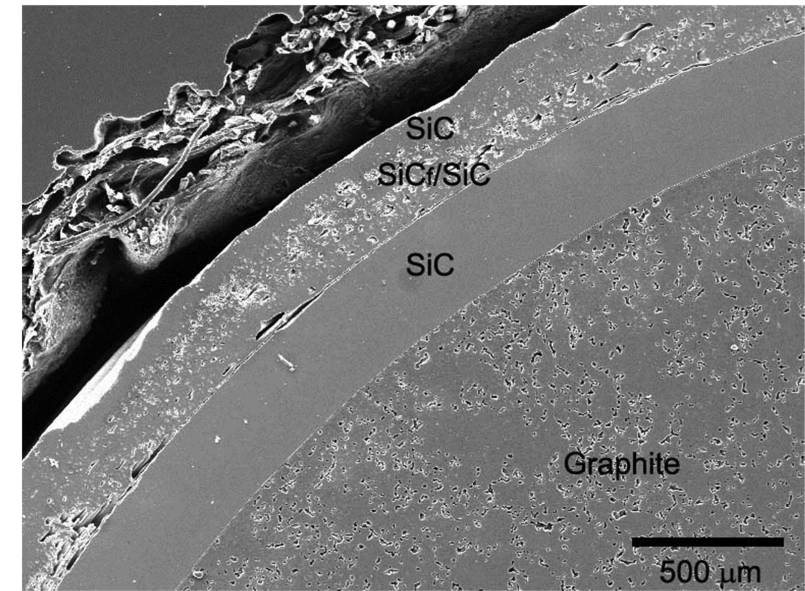

Fig. 5. Typical microstructure of the multi-layered SiC composite.

플의 경우는 두 번째 단위층을 $+55^{\circ}$ 방향으로 권선할 때, $-55^{\circ}$ 방향의 $\mathrm{SiC}$ 섬유는 $1 / 2$ 면적만큼 채워져 있으며, 또 한 이들을 완전하게 압착시키기에 장력이 불충분한 것으 로 보인다. $\mathrm{SA3}-\mathrm{S} 1116 \mathrm{PX} \mathrm{SiC}$ 섬유는 $\mathrm{SA} 3-\mathrm{S} 1108 \mathrm{PX}$ 에 비 해 섬유 부피 분율이 최대 약 $10 \%$ 까지 떨어진 것을 볼 수 있다. 이는 장력이 크게 부과되지 않았기 때문에 같은 권선 패턴을 가지더라도 섬유의 퍼짐 현상(spreading)이 800 필라멘트로 이루어진 SA3-S1108PX 섬유에 비해 적 게 발생하고, 섬유의 필라멘트 수가 SA3-S1I08PX에 비해 많기 때문에 압착도 충분히 일어나지 않았기 때문으로 판 단된다.

\section{3. 섬유 권선 방법에 따른 표면조도 변화}

Fig. 5 는 화학기상침착을 15 시간 수행한 후 $\mathrm{SiC}_{\mathrm{f}} / \mathrm{SiC}$ 복 합체의 미세구조를 보여주고 있다. 화학기상침착에 의해 복합체의 밀도는 약 $90 \%$ 까지 채워졌음을 볼 수 있다. $\mathrm{SiC}$ 최외각층의 두께는 약 $30 \mathrm{~mm}$ 로 측정되었으며, 복합체 표 면에 균일한 두께로 증착 되어 있어 복합체의 표면 형태 를 잘 반영하고 있다고 볼 수 있다.

$\mathrm{SiC}$ 복합체 튜브 표면의 산술평균조도(Arithmetical Mean Roughness, $\mathrm{R}_{\mathrm{a}}$ )는 식 (2)와 같이 $25 \mathrm{~mm}$ 측정구간 $(l)$ 의 중 심값으로부터 아래와 위 부분의 전체면적을 구한 다음, 측정구간의 길이로 나눈 값을 취했다.

$$
R_{a}=\frac{1}{l} \int_{0}^{l}|f(x)| d x
$$

Fig. 6는 6-return 패턴을 가지는 SA3-S1I16PX 섬유가 권선된 $\mathrm{SiC}_{\mathrm{f}} / \mathrm{SiC}$ 복합체의 표면조도 측정값 및 산술평균 조도 값을 보여준다.

Fig. 7과 Fig. 8은 SA3-S1108PX와 SA3-S1I16PX SiC 섬유가 권선된 $\mathrm{SiC}_{\mathrm{f}} / \mathrm{SiC}$ 복합체의 권선패턴에 따른 표면

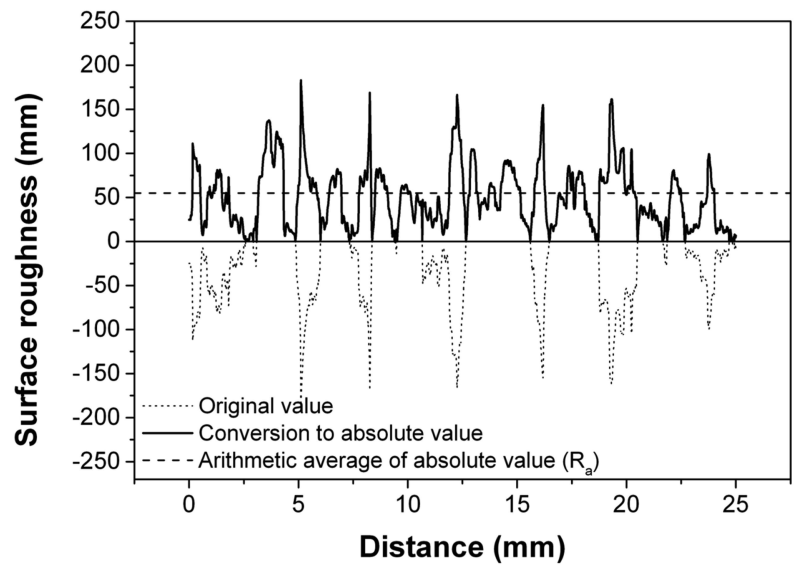

Fig. 6. Roughness curves to obtain the arithmetic average of absolute value of the $\mathrm{SiC}_{\mathrm{f}} / \mathrm{SiC}$ composite reinforced by SA3-S1I16PX SiC fiber.

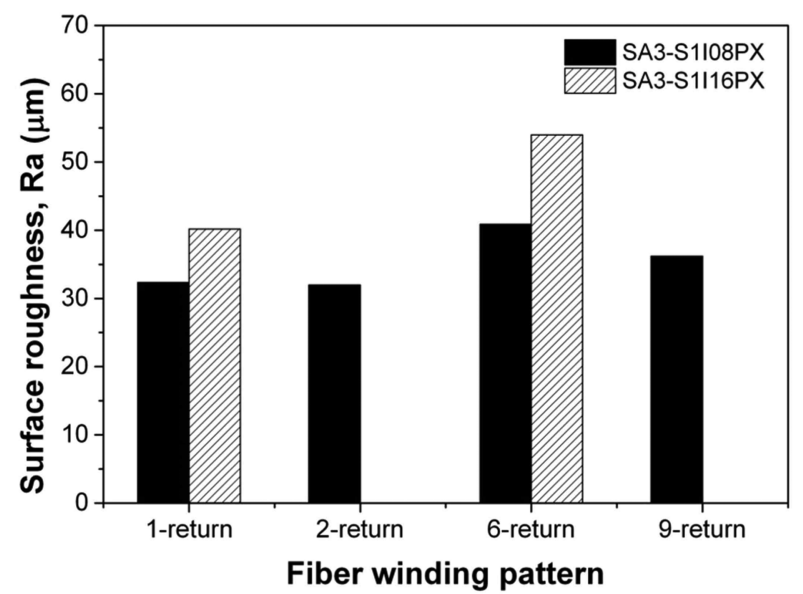

Fig. 7. Surface roughness of $\mathrm{SiC}_{\mathrm{f}} / \mathrm{SiC}$ composite tubes reinforced by Tyranno SA3-S1I08PX and Tyranno SA3S1I16PX SiC fibers.

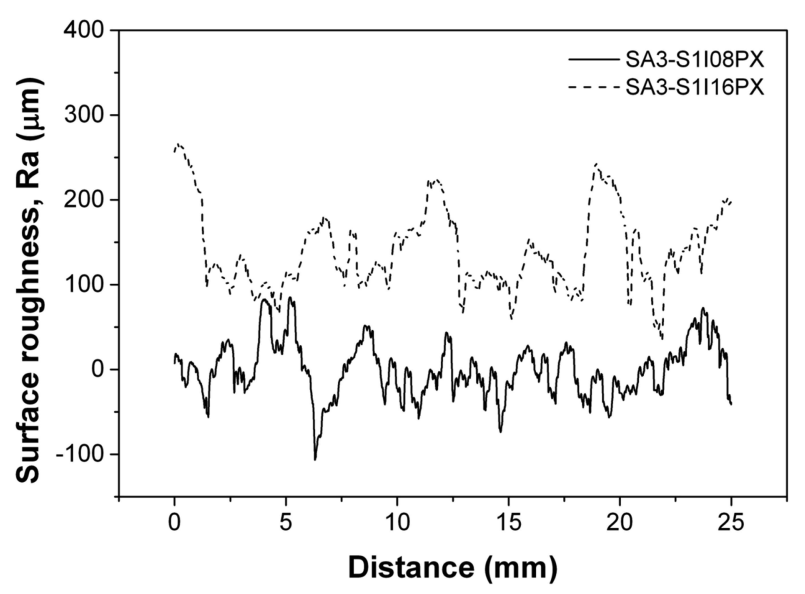

Fig. 8. Surface roughness of the 1-return patterned $\mathrm{SiC}_{\mathrm{f}} / \mathrm{SiC}$ composites reinforced by SA3-S1I08PX and SA3S1I16PX SiC fibers wound with $+55 /-55^{\circ}$ angle. The roughness curves were vertically shifted for clarity. 
조도 변화를 보여주고 있다. SA3-S1I08PX 섬유가 와인딩 된 복합체의 경우 1-return과 2-return 샘플에서 거의 동일 한 표면조도 값 $(1$-return $=32.3 \mu \mathrm{m}, 2$-return $=32.0 \mu \mathrm{m})$ 을 얻을 수 있었다. 이는 권선 패턴이 거의 동일하기 때문이 다. 그러나, 6-return 및 9-return 시편의 경우 표면조도가 $40.6 \mu \mathrm{m}$ 및 $36.2 \mu \mathrm{m}$ 로 상승하였다. 표면 조도는 섬유 부 피 분율과도 밀접한 관계가 있으며, 9-return의 경우 Fig. 3(d)에서도 볼 수 있는 바와 같이, 첫 번째 단위 층 의 빈 공간(winding pitch)에 두 번째 단위 층이 권선 되 는데, 이 때 두 단위 층이 완전히 압착될 만큼의 충분한 섬 유 장력이 인가되지 않기 때문에, 단위 층 간의 높낮이 차 이가 발생하게 된다. 6-return 샘플 역시 첫 번째, 두 번째, 세 번째 단위 층이 모두 표면에 드러나게 되고(Fig. 3(c)), 이들의 높낮이 차이로부터 큰 표면조도를 야기한 것으로 보인다.

$\mathrm{SiC}$ 섬유의 필라멘트 수 역시 표면조도에 큰 영향을 미 친 것을 볼 수 있다. 같은 권선 패턴을 가지는 SA3$\mathrm{S} 1 \mathrm{I} 08 \mathrm{PX}$ 와 $\mathrm{SA} 3-\mathrm{S} 1116 \mathrm{PX} \mathrm{SiC}$ 섬유 복합체의 경우, 필라 멘트 수가 증가함에 따라 표면조도는, 1-return 샘플과 6return 샘플에서 각각 $19.5 \%$ 와 $24.3 \%$ 증가했다. 필라멘트 수가 많을수록 $\mathrm{SiC}$ 섬유의 두께가 두꺼워지기 때문에, 섬 유 자체의 높낮이 차이가 크게 발생한다(Fig. 6). 또한, 필 라멘트 수가 많은 섬유일수록 권선 시 장력에 의한 섬유 의 퍼짐이 잘 이루어지지 않기 때문에 1600 필라멘트에 서 더욱 불균일한 표면구조가 관찰이 된다(Fig. 8).

\section{4. 결 론}

Tyranno SA3급의 $\mathrm{SiC}$ 섬유인 $\mathrm{SA3}-\mathrm{S} 1 \mathrm{I} 08 \mathrm{PX}$ 와 SA3$\mathrm{S} 1116 \mathrm{PX}$ 을 이용하여 $\mathrm{CVD} \mathrm{SiC}$ 가 코팅된 흑연 맨드릴에 $+55 /-55^{\circ}$ 각도의 나사선 형태로 필라멘트 와인딩을 수행 하였다. $\mathrm{SiC}$ 섬유 프리폼을 화학기상침착법(CVI)으로 $\mathrm{SiC}$ 기지상을 침착시킨 후, 표면조도와 섬유의 부피 분율을 측정하였다.

대나무 형상의(bamboo-like) 패턴으로 $\mathrm{SiC}$ 섬유가 권선 될 경우, 지그재그 패턴보다 섬유의 부피 분율이 크게 높 아졌다. 이는 지그재그 패턴을 가질 경우 단위 층들 사이 가 완전히 압착되지 않는 반면, 대나무 형상의 패턴의 경 우 $+55^{\circ}$ 각도의 섬유와 $-55^{\circ}$ 각도의 섬유가 간섭이 없이 섬유가 감기기 때문이다. 동일한 원인에 의해 표면조도 역시 상승하였다.

1600 필라멘트로 이루어진 SA3-S1I16PX SiC 섬유를 이 용해 섬유 프리폼을 제조할 경우, 표면조도는 800 필라멘 트의 SA3-S1I08PX SiC 섬유에 비해 약 $20 \%$ 이상 상승
하였으며, 섬유 부피 분율 역시 감소하였다.

\section{Acknowledgment}

섬유 권선 실험에 도움을 주신 한국에너지기술연구원 의 한인섭 박사님, 김세영님께 진심으로 감사 드립니다. 이 논문은 2013년도 정부(미래창조과학부)의 재원으로 한 국연구재단의 지원을 받아 수행된 연구입니다(원자력연구 개발사업, No. 2012M2A8A5009818).

\section{REFERENCES}

1. K. Yueh, D. Carpenter, and H. Feinroth, "Clad in Clay," Nucl. Eng. Int., 55 14-16 (2010).

2. W.-J. Kim, D. Kim, and J. Y. Park, "Fabrication and Material Issues for the Application of SiC Composites to LWR Fuel Cladding," Nucl. Eng. Technol., 45 [4] 565-72 (2013).

3. W.-J. Kim, S. M. Kang, K. H. Park, A. Kohyama, W. -S. Ryu, and J.Y. Park, "Fabrication and Ion Irradiation Characteristics of SiC-Based Ceramics for Advanced Nuclear Energy Systems (in Korean)," J. Kor. Ceram. Soc., 42 [8] 575-81 (2005).

4. C. R. F. Azevedo, "Selection of Fuel Cladding Material for Nuclear Fission Reactors," Eng. Failure Anal., 18 [8] 194362 (2011).

5. D. Kim, J. Lee, W.-J. Kim, S.G. Yoon, and J.Y. Park, "Deposition of $\beta$-SiC by a LPCVD Method and the Effect of the Crystallographic Orientation on Mechanical Properties (in Korean)," J. Kor. Ceram. Soc., 50 [1] 43-49 (2013).

6. H. Feinroth, M. Ales, E. Barringer, G. Kohse, D. Carpenter, and R. Jaramillo, "Mechanical Strength of CTP Triplex SiC Fuel Clad Tubes after Irradiation in MIT Research Reactor under PWR Coolant Conditions"; pp. 47-58 in Silicon Carbide and Carbon Composites, Vol. 30, Ceramic Engineering and Science Proceeding, Ed. by Y. Katoh and A. Cozzi, John Wiley \& Sons, New Jersey, 2009.

7. Y. Katoh, T. Nozawa, L. L. Snead, K. Ozawa, and H. Tanigawa, "Stability of SiC and Its Composites at High Neutron Fluence," J. Nucl. Mater., 417 [1-3] 400-05 (2011).

8. D. Shaw-Stewart, "Filament Winding - Materials \& Engineering," Mater. Des., 6 [3] 140-44 (1985).

9. C. Ayranci and J. Carey, "2D Braided Composites: A Review for Stiffness Critical Applications," Compos. Struct., 85 [1] 43-58 (2008).

10. M. Lossie and H.V. Brussel, "Design Principles in Filament Winding," Compos. Manuf., 5 [1] 5-13 (1994).

11. P. D. Soden, R. Kitching, P. C. Tse, and Y. Tsavalas, "Influence of Winding Angle on the Strength and Deformation of Filament-Wound Composite Tubes to Uniaxial and Biaxial Load," Compos. Sci. Technol., 46 [4] 363-78 (1993). 